\title{
BRAIN STEM ACTIVATION OF THE HIPPOCAMPUS: A ROLE FOR THE MAGNOCELLULAR RETICULAR FORMATION AND THE MLF ${ }^{1}$
}

\author{
ROBERT P. VERTES \\ Department of Physiology, University of Michigan Medical School, Ann Arbor, Mich. 48109 (U.S.A.)
}

(Accepted for publication: March 13, 1980)

In previous reports (Vertes 1977,1979 ) we have shown that a large percentage of brain stem neurons lying within the pontine and medullary magnocellular field discharge at high rates of activity during both waking with movement (W-M) and REM sleep and at low rates during quiet waking and slow wave sleep. We initially suggested (Vertes 1977) that some of these brain stem cells may be involved in the activation of the theta rhythm of the hippocampus, since they discharged maximally during the identical states in which theta is present in the hippocampus of the rat, i.e., during movement and REM sleep (Vanderwolf 1969; Winson 1972) ${ }^{2}$. Our hypothesis was strengthened by our recent description (Vertes 1979) of a type of magnocellular reticular neuron that fired tonically during W-M and REM and which showed discharge characteristics remarkably parallel to properties attributed to hippocampal theta. Specifically, during W-M increased tonic cell discharge and the theta rhythm were present during a wide variety of apparently independent motor acts. During REM sleep high frequency cell discharge was correlated with a very regular, sinusoidal theta rhythm while low frequency discharge was correlated with

\footnotetext{
${ }^{1}$ Supported primarily by NSF Grant BNS 78-10136 and in part by Biomedical Research Support Grant RR05383.

2 The term 'theta' is not used here in its officially accepted form but to mean a frequency range in the rat of $6-12 \mathrm{c} / \mathrm{sec}$.
}

irregular theta. Petsche and co-workers (Petsche et al. 1962, 1965; Stumpf et al. 1962) were the first to show that burstingtype cells in the medial septum are involved in the generation of hippocampal theta and that these septal cells are, in turn, dependent upon input arising from the brain stem for their activation.

Although several studies (Polc and Monnier 1970; Klemm 1972; Macadar et al. 1974; Paiva et al. 1976; Robinson and Vanderwolf 1978) have shown that stimulation over widespread areas of the brain stem is capable of eliciting a theta rhythm in the hippocampus, the exact site(s) of the cells responsible for this effect still remains unresolved. For instance, two recent reports (Macadar et al. 1974; Robinson and Vanderwolf 1978) that have analyzed the effect of stimulation of specific brain stem nuclei on hippocampal activity have reached quite opposite conclusions. Macadar et al. (1974) in the anesthetized cat reported that stimulation of nucleus pontis caudalis and median raphe produced hippocampal desynchronization while locus coeruleus stimulation resulted in hippocampal synchronization. In contrast to this, Robinson and Vanderwolf (1978) in the freely moving rat reported that the nucleus pontis caudalis and median raphe were among their most effective locations for eliciting hippocampal synchronization while stimulation of locus coeruleus was ineffective in driving theta or effective only at very high levels of current.

In the present study, we have attempted to 
resolve previous differences and to precisely localize the origin of the brain stem cells involved in theta generation by mapping the entire brain stem with stimulation and determining its effect on hippocampal slow wave activity. Stimulation sites were carefully analyzed to determine both the site(s) of origin of the brain stem cells affecting the hippocampus and the fiber bundles through which these cells travel in their route rostrally from the brain stem. In order that our results could be directly compared to previous work in the anesthetized cat (Macadar et al. 1974) this study was conducted in the anesthetized rat. Further, since brain stem stimulation is very effective in producing movement (Ward 1958; Bernston and Micco 1976; Robinson 1978), conducting the study in the moving rat would have run the risk that theta-eliciting sites would be effective not because they activated cells directly involved in the generation of the theta rhythm, but because they induced movement. The results showed that the most effective sites for eliciting hippocampal theta were located within the medial magnocellular reticular formation (MMRF) and in or near the medial longitudinal fasciculus (MLF) at the pontine level. These results suggest that cells of the MMRF are critically involved in theta generation and that the fibers of these theta-eliciting cells primarily ascend via the MLF.

\section{Methods}

\section{Preparation for stimulation}

Under sodium pentobarbital anesthesia, rats were permanently fitted with bipolar bilateral dorsal hippocampal electrodes $(0.005$ in. stainless steel [SS] wires), a cortical skull screw for recording the EEG and a ground screw. The tips of the bipolar hippocampal electrodes were separated by approximately $0.75-1.0 \mathrm{~mm}$ and were aimed at the two hippocampal subfields in which the theta rhythm can be recorded at its maximal amplitude in the rat, i.e., ventrally the stratum moleculare of the dorsal blade of the dentate gyrus and dorsally the stratum oriens (Winson 1974, 1976; Bland and Wishaw 1976). After the rats recovered from surgery the efficacy of the hippocampal electrodes in recording the theta rhythm was tested as rats freely moved about in a 34 in. $X 45$ in. enclosure. Only those rats showing a distinct high amplitude theta rhythm ( $1 \mathrm{mV}$ or more) in at least one pair of the bipolar hippocampal electrodes were used in the subsequent stimulation phase of the experiment. Mapping could be carried out in rats with only a single pair of effective hippocampal leads since unilateral brain stem stimulation always bilaterally affected the hippocampus. In $70-80 \%$ of the rats, however, high amplitude theta could be recorded from both pairs of hippocampal leads.

\section{Procedure for stimulation}

For stimulation, rats were first anesthetized with either methoxyflurane (25 rats) or urethane (16 rats). A small anesthesia machine (Snyder Veterinary Products Co., Taos NM, Model M-7550) was used to administer the methoxyflurane. The urethane was given i.p. $(1.2 \mathrm{~g} / \mathrm{kg})$. With these anesthetics rats could be maintained at relatively constant levels of anesthesia for the duration of the experiment. The results obtained with these two anesthetic agents were comparable. Following anesthesia, rats were placed in a stereotaxic instrument and small holes (4-6/rat) were drilled through the skull over select regions of the brain stem. Bipolar stimulating electrodes ( 0.005 in. SS wires separated by $0.5-1.0 \mathrm{~mm}$ and insulated except for their exposed tips) were lowered through each hole and stimulation was delivered at each $0.5 \mathrm{~mm}$ descent through the brain stem. Rectangular pulses $(0.2 \mathrm{msec}, 300 \mathrm{~Hz})$ were applied (mono- or bipolar) for a 4-6 sec duration at each stimulus location. Activity from each side of the hippocampus was recorded and written out on a Grass polygraph at a fast paper speed (25 $\mathrm{mm} / \mathrm{sec}$ ) 5-15 sec before, $4-6 \mathrm{sec}$ during, and 5-15 sec after each stimulation. The inter-stimulus interval was $1-2 \mathrm{~min}$. 
In order to directly compare the effect of stimulation of one brain stem area with another, all locations were stimulated at the two constant currents of $50 \mu \mathrm{A}$ and $100 \mu \mathrm{A}$. These values were chosen as the result of preliminary work which showed that stimulation within the 50-100 $\mu \mathrm{A}$ range produced a theta rhythm that was very comparable in frequency and amplitude to that present under normal awake conditions (see Fig. 4). Stimulation at less than $50 \mu \mathrm{A}$ was generally ineffective at altering hippocampal activity. Stimulation in the range of $150 \mu \mathrm{A}$ or greater frequently resulted in very fast hippocampal activity $(>12 \mathrm{c} / \mathrm{sec})$ and often produced desynchronization at sites which at lower currents produced synchronization. The general procedure was to adjust the current to 100 $\mu \mathrm{A}$ in the descending stimulation series and to re-stimulate at $50 \mu \mathrm{A}$ in the ascending series. All brain stem locations (see Fig. 3) were stimulated at least twice and critical regions (MLF, MMRF and monoaminergic nuclei) were mapped 5-10 times.

Temperature was continuously monitored and maintained at $37.0-38.0^{\circ} \mathrm{C}$. The ECG was recorded and written out on a separate polygraph channel. Each brain stem site was analyzed to determine whether its stimulation synchronized, desynchronized or had no effect on hippocampal slow wave activity. If synchronization resulted, the frequency was determined. This was done by counting the frequency of the theta rhythm for the first $3 \mathrm{sec}$ following the onset of the stimulation at each synchronizing site. The Prussian Blue method was used to mark electrode locations as previously described (Vertes 1977, 1979). Sixty micron frozen sections were stained with either luxol fast blue-cresyl violet, or basic fuchsin.

\section{Results}

The results show that in those instances when brain stem stimulation altered the activity of the hippocampus, the predominant effect was that of synchronization, i.e., the elicitation of a hippocampal theta rhythm. This synchronizing effect is illustrated in Figs. 1 and 2 which show the locations of 3 mediallaterally aligned mid-pontine sites (Fig. 1) and the effect of their stimulation on hippocampal activity (Fig. 2). It can be seen in Figs. 1a and $2 \mathrm{a}$ that stimulation within the medial magnocellular fields elicits a distinct high amplitude theta rhythm that begins almost immediately with stimulus onset and lasts for the duration of the stimulation. The periods both before and after the stimulation are characterized by slow $(<6 \mathrm{c} / \mathrm{sec})$ or irregular hippocampal activity. Virtually the same effect that was elicited by pontis caudalis stimulation was elicited from stimulation of a region just below the medial longitudinal fasciculus (MLF) (Figs. 1b and 2b). In contrast to the medial sites, stimulation in the lateral pontine field (Figs. 1c and 2c), approximately $2 \mathrm{~mm}$ from the midline, produced essentially no change in hippocampal activity.

The locations mapped on the 8 coronal sections of Fig. 3 summarize the effects that were obtained from stimulation of the extent of the brain stem. The main findings as shown in this figure were the following: (1) Brain stem sites in or near the MLF at the pontine and caudal midbrain level were among the most effective for eliciting hippocampal theta. Fig. 3 shows that the effectiveness of MLF stimulation in driving theta is progressively enhanced at successive rostral levels of the brain stem. This result is further illustrated in Fig. 4 which compares the effect produced by dorsal midline (MLF) stimulation at 4 separate brain stem levels. At caudal medullary levels the stimulation elicited a slight synchronization that is below theta frequency of $6-12$ c/sec (sect. 8) or just at $6 \mathrm{c} / \mathrm{sec}$ (sect. 6). A distinct theta rhythm $(7-8 \mathrm{c} / \mathrm{sec})$ is evident at the level of the rostral medulla (sect. 4) and is even more pronounced $(>8 \mathrm{c} / \mathrm{sec})$ with MLF stimulation at the mid-pontine level (sect. 2). The effects shown here (and in Fig. 2) were highly reproducible and site specific. The high frequency theta obtained at the mid-pontine 


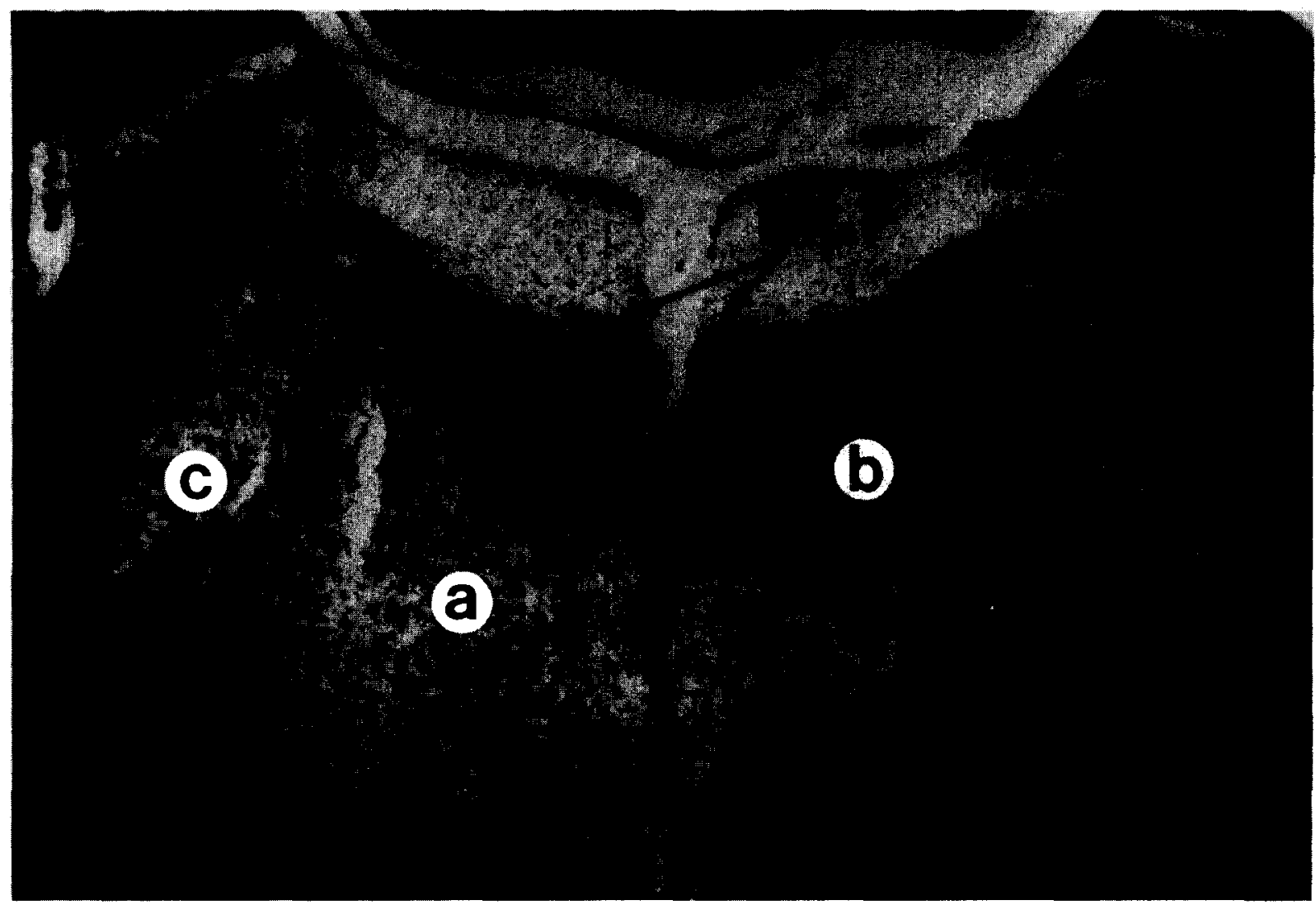

Fig. 1. Photomicrograph of a coronal section through the mid-pons showing the location of 3 mediolaterally aligned pontine stimulation sites (see arrows). The 3 electrode tracts can be seen. The effect of stimulation on hippocampal activity at these sites is shown in Fig. 2. Section was stained using the Klüver-Barrera technique for cells and fibers.

level continued to be elicited along the rostral extent of the MLF (see Fig. 3). It should be noted that the distinct theta rhythm shown in Fig. 4 (sect. 2 and 4 ) is very comparable to that shown by the freely moving rat (Fig. 4, top trace). (2) The most effective sites for eliciting theta in or near cells or nuclei (as opposed to fiber bundles) were those within the medial magnocellular reticular formation (MMRF). A theta rhythm of 6-7 $\mathrm{c} / \mathrm{sec}$ could be elicited from stimulation of the medullary nucleus gigantocellularis (NGC). At caudal NGC levels the effective locations were concentrated ventrally, while at more rostral sites they encompassed the entire NGC field dorsoventrally. Stimulation throughout the pontine magnocellular field was very effective at producing theta as demonstrated by the RPC location of Figs. 1a and $2 \mathrm{a}$. The most effective synchronizing sites along the magnocellular chain of cells were those within the nucleus pontis oralis (RPO). (3) Several brain stem areas were clearly ineffective at altering hippocampal activity. These included reticular nuclei lateral to the magnocellular nuclei, the cranial nerve nuclei (including the vestibular nuclei), and monaminergic nuclei such as the dorsal raphe and locus coeruleus. (4) The only locations which consistently produced desynchronization were those situated within the median raphe nucleus. Desynchronization at this site was 

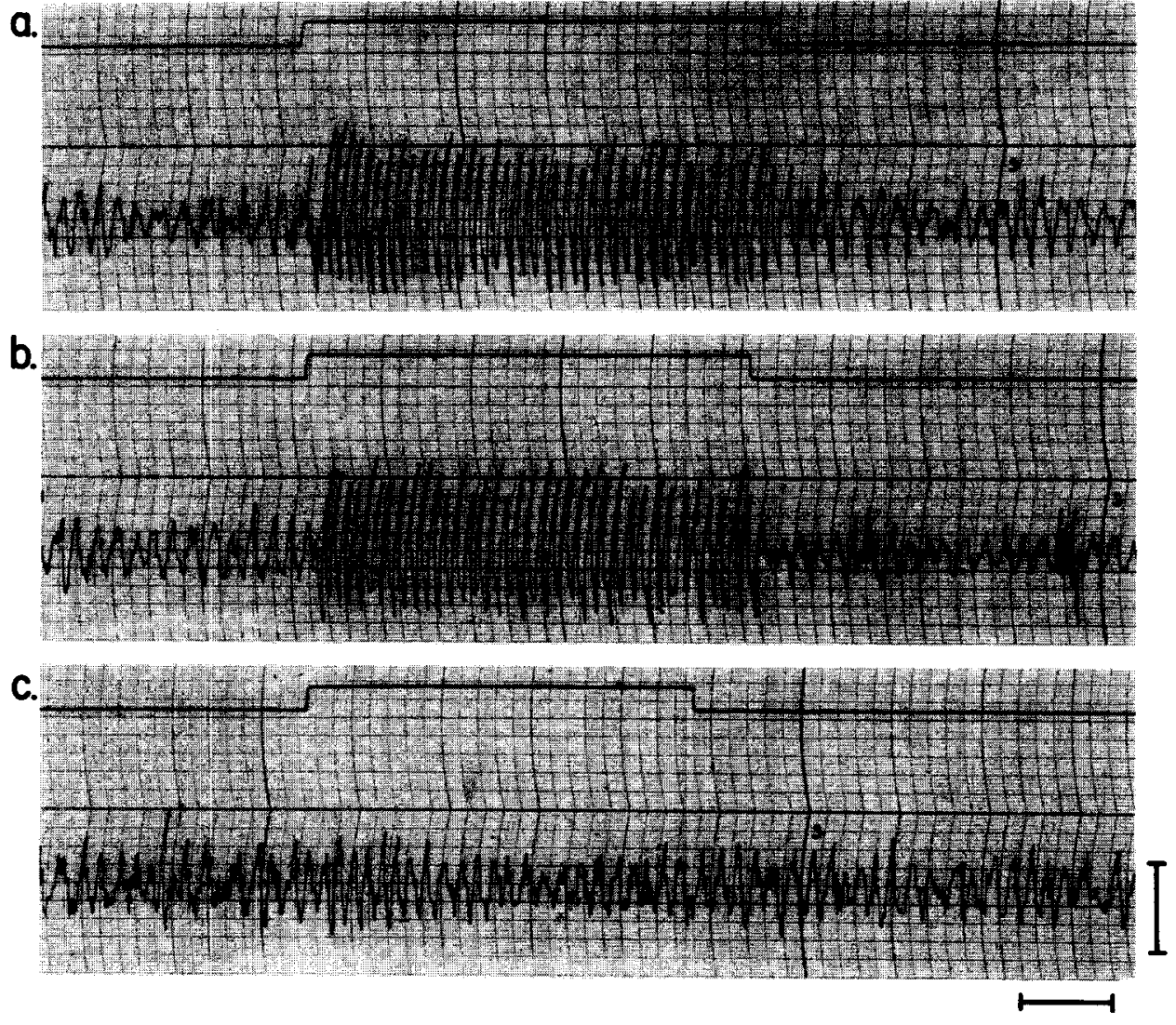

Fig. 2. Effect of stimulation $(100 \mu \mathrm{A})$ on hippocampal activity at the 3 locations depicted in Fig. 1 . Letters correspond to the lettered sites of Fig. 1. Upper line (in a, b, and c) is a signal marker denoting the period of stimulation and lower line is the slow wave activity of the hippocampus. A distinct theta rhythm was elicited from stimulation within the pontine magnocellular field (a) and from stimulation on the midline just below the MLF (b) but no change in hippocampal activity resulted from stimulation in the lateral pontine tegmentum (c) at the level of and approximately $1 \mathrm{~mm}$ lateral to the effective magnocellular site. Calibrations: 1 sec and $1 \mathrm{mV}$.

accompanied by significant decreases in the amplitude of hippocampal activity. (5) At the level of the rostral pons-caudal midbrain (Fig. 3, sect. 1-2) the area from which synchronization could be elicited expands both laterally and dorsally. Synchronization produced by the dorsal locations (lateral to the central grey) most likely results from the activation of fibers originating from more caudally placed cells. (6) Although the dorsal midline points close to the MLF were the most effective for activating theta, a pronounced theta rhythm could also be elicited from midline regions below the MLF.

As indicated, the results shown in Fig. 3 were obtained with the current set at $100 \mu \mathrm{A}$. Stimulation at $50 \mu \mathrm{A}$ was very much less effective in altering hippocampal activity than $100 \mu \mathrm{A}$ stimulation at all brain stem sites. At very effective synchronizing sites (triangles and squares of Fig. 3) $50 \mu \mathrm{A}$ stimulation generally produced slow wave activity that was just at or below theta range $(6-12 \mathrm{c} / \mathrm{sec})$ while at less effective sites (circles of Fig. 3 ) $50 \mu \mathrm{A}$ stimulation elicited only very slight changes in the hippocampal EEG. Stimulation 


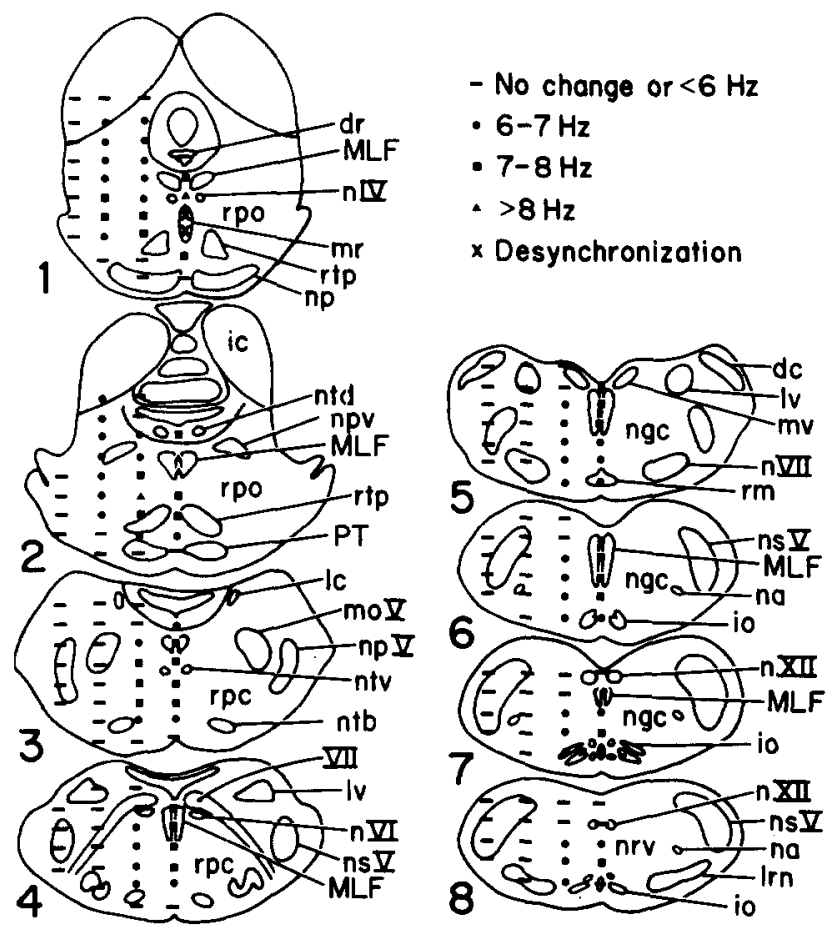

Fig. 3. Schematic coronal sections (separated by approximately $1 \mathrm{~mm}$ ) through the brain stem showing the areas that were stimulated and the effect this stimulation $(100 \mu \mathrm{A})$ had on hippocampal slow wave activity. The most effective theta-eliciting sites were within the nucleus pontis oralis and in or just below the MLF (see triangles, sections 1, 2). Schematic sections were slightly modified from those of Palkovits and Jacobowitz (1974). Abbreviations: dc, dorsal cochlear; dr, dorsal raphe; ic, inferior colliculus; io, inferior olive; lc, locus coeruleus; lrn, lateral reticular nucleus; lv, lateral vestibular; MLF, medial longitudinal fasciculus; mo V, motor trigeminal; mr, median raphe; mv, medial vestibular; na, nucleus ambiguus; ngc, nucleus gigantocellularis; np, nucleus pontis; nvp, ventral parabrachial nucleus; np V, principal trigeminal; nrv, reticularis ventralis; $n s \mathrm{~V}$, spinal trigeminal; ntb, nucleus of trapezoid body; ntd, dorsal tegmental (Gudden); ntv, ventral tegmental (Gudden); $n$ IV, trochlear nucleus; $n$ VI, abducens nucleus; n VII, facial nucleus; VII, facial nerve; $n$ XII, hypoglossal nucleus; PT, pyramidal tract; rm, raphe magnus; rpc, reticularis pontis caudalis; rpo, reticularis pontis oralis; rtp, pontine tegmental nucleus.

at $50 \mu \mathrm{A}$ resulted in the same relative distribution of effective synchronizing sites as did $100 \mu \mathrm{A}$ stimulation.

\section{Discussion}

The most effective brain stem sites for producing hippocampal synchronization were those within the medial magnocellular reticular formation (MMRF) and in or near the MLF at the pontine level. This was demonstrated by the fact that the theta rhythm could be driven at higher frequencies from stimulation of the MMRF and the MLF than it could from stimulation of other locations in the brain stem. In accord with a previous report (Paiva et al. 1976) in which the mesand diencephalon were stimulated in the cat, we found that stimulating at constant levels of current and monitoring changes in the frequency of the theta rhythm was a very sensitive way of comparing the relative effectiveness of brain stem synchronizing sites.

The very effective theta-eliciting sites within the medial magnocellular reticular chain, primarily pontis oralis and pontis caudalis and to a lesser extent rostral nucleus gigantocellularis, suggest that these nuclei are critically involved in hippocampal theta gener- 


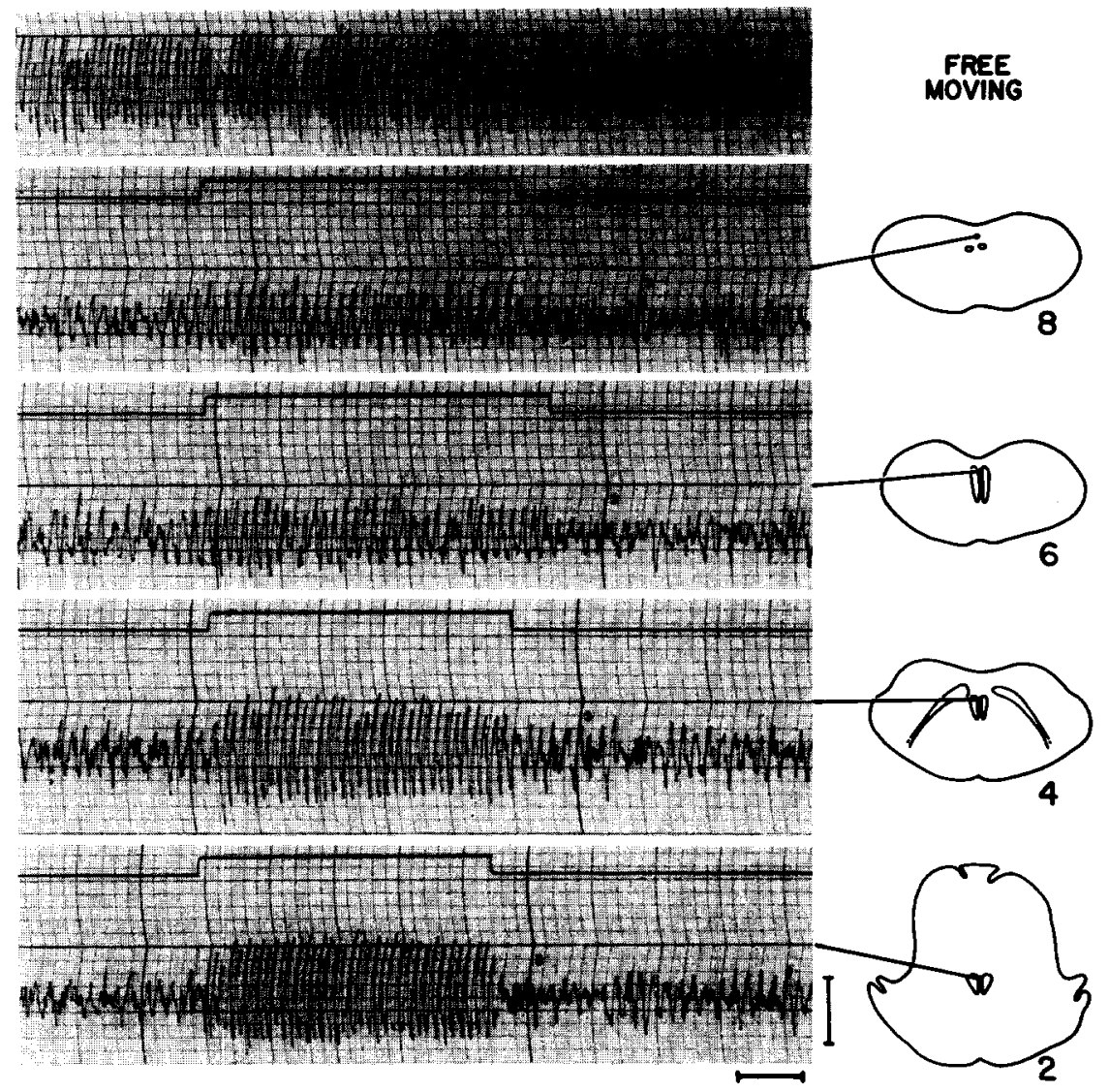

Fig. 4. Effect on hippocampal activity of dorsal midline (MLF) stimulation (100 $\mu \mathrm{A})$ in one rat at 4 rostro-caudally aligned brain stem locations each separated by approximately $2 \mathrm{~mm}$. Schematic sections to right show sites of stimulation (numbers refer to sections of Fig. 3). The stimulation becomes progressively more effective at synchronizing hippocampal activity at successive rostral levels of the brain stem. Calibrations: 1 sec and $1 \mathrm{mV}$.

ation. These results obtained with stimulation are consistent with our previous findings showing that single MMRF cells discharge selectively during the identical states of waking movement and REM sleep in which the theta rhythm is present in the hippocampus of the rat. Arnolds et al. (1977), in the freely behaving dog, have reported a correlation between pontine reticular activity (multiunit) and the theta rhythm of the hippocampus. These authors have also suggested that cells within the pontine reticular formation may be involved in hippocampal theta generation.

The finding that theta was so effectively elicited by stimulation within or near the
MLF was unexpected. In studies comparable to the present one (Polc and Monnier 1970; Klemm 1972; Macadar et al. 1974; Robinson and Vanderwolf 1978) the MLF has never been mentioned as an effective hippocampal synchronizing (or desynchronizing) site. Furthermore, the ascending MLF has generally been considered as an important pathway linking the vestibular nuclei with the oculomotor nuclei (Brodal and Pompeiano 1957; McMasters et al. 1966; Carpenter 1971) and has not been thought to carry information that could affect forebrain structures such as the hippocampus. Recent evidence suggests that a significant number, and possibly a ma- 
jority, of the cells of the MMRF (at least those at the pontine level) send their axons via the MLF and these fibers may be responsible for the synchronizing effect elicited by MLF stimulation.

Remmel et al. (1978) recently reported that MLF stimulation in the region of the trochlear nucleus antidromically activated cells on both sides of the MMRF at the pontine level. This confirms an earlier report by Nozue and Cohen (1968) using similar electrophysiological techniques which showed that 500 out of 800 PRF (PRF = pontine reticular formation) cells encountered were affected by MLF stimulation, and concluded that '... the MLF carries axons of cells which lie in the PRF.' Anatomical studies tracing the efferent connections of the MMRF have yielded similar results. Using degeneration techniques, Nauta and Kuypers (1958) (Nauta-Gygax method) found that cells from the MMRF ascend ventrolateral to the MLF in Forel's bundle, while Matano (1970) using the Marchi technique showed that pontine reticular fibers ascend both in Forel's bundle (lateral to the MLF) and in the MLF itself. In a recent autoradiographic study in the cat, Graybiel (1977) describes two main groups of fibers ascending from the pontine MMRF, one running laterally, medial to the superior olive, and the other in or near the confines of the MLF largely but not exclusively on the contralateral side.' In the monkey ascending fibers from the MMRF were shown to project in a compact bundle close to the midline and ventral to the MLF (Buttner-Ennever and Henn 1976).

Although sites near the MLF were the most effective midline locations for generating theta, a pronounced theta rhythm could also be elicited by stimulation on the midline below the MLF. This could indicate that fibers involved in theta generation course through the brain stem along essentially the entire dorsoventral extent of the midline, but are concentrated dorsally in or near the MLF. A more likely possibility is that stimulation at these ventral midline sites activates reticular fibers of crossing. Walberg (1974) has shown that a large number of reticular fibers cross the midline to the contralateral reticular formation along the entire length of the brain stem from the medulla to the mesencephalon. It is also conceivable that theta-eliciting midline stimulation activates cells or fibers belonging to the nuclei of the raphe. This is a distinct possibility for the caudal raphe groups, at least, since the locations of some of their cells overlap with regions from which theta could be elicited. We did show, however, that stimulation of the two prominent rostral nuclei, dorsal and median raphe, which project profusely to the forebrain (Conrad et al. 1974; Azmitia and Segal 1978) did not produce hippocampal synchronization. Robinson and Vanderwolf (1978) have shown that the administration of $p$-CPA (inhibits 5-HT synthesis) did not alter the threshold at which brain stem stimulation elicited hippocampal theta. This also argues against a critical role for the raphe nuclei in hippocampal synchronization.

\section{Comparisons with previous studies}

In this report median raphe stimulation was shown to produce hippocampal desynchronization. This confirms previous reports in both the rat (Assaf and Miller 1978) and cat (Macadar et al. 1974) in which MR stimulation also desynchronized hippocampal activity. In addition, it is consistent with the finding of Maru et al. (1979) which showed that MR-lesioned rats exhibit a continuous theta rhythm during behavioral immobility. In contrast to the above findings, Robinson and Vanderwolf (1978) reported that stimulation of the median raphe produced hippocampal synchronization. These authors mentioned, however, that MR stimulation elicited both theta activity and movement (Robinson 1978; Robinson and Vanderwolf 1978). Since theta is correlated with motor behavior in the rat (Vanderwolf 1969) it is possible that the desynchronizing effects of MR stimulation were masked by a movement-induced synchronization. 
In the present report it was shown that pontis caudalis (RPC) stimulation elicited a distinct theta rhythm while locus coeruleus (LC) stimulation had no effect on hippocampal slow wave activity. These results essentially correspond to work in the moving rat (Robinson and Vanderwolf 1978) but differ substantially from the results of Macader et al. (1974) in the cat. In the cat LC was a very effective theta-eliciting site while RPC stimulation produced hippocampal desynchronization. Since the present report and the one in the cat were similar in most respects including the use of anesthetized animals, species differences could account for conflicting results. A possible species difference in brain stem structures involved in hippocampal synchronization could underlie the known species difference in the behavioral correlates of the theta rhythm (Winson 1972). For instance in the rat in which theta is correlated with movement, the structure most responsible for theta activation could be the motor-associated (Ward 1958; Bernston and Micco 1976; Siegel and McGinty 1977; Vertes 1977, 1979; Robinson 1978) magnocellular reticular formation. In the cat the theta rhythm is correlated with orientation or attention (Bennett 1969). In this species, the locus coeruleus - whose cells have been shown to respond to attention-eliciting sensory stimuli (Foote et al. 1978; Jones et al. 1978) - could be the nucleus most involved in hippocampal synchronization.

In conclusion the present results together with previous findings (Polc and Monnier 1970; Klemm 1972; Macadar et al. 1974; Arnolds et al. 1977; Vertes 1977, 1979; Robinson and Vanderwolf 1978) strongly suggest that cells within the magnocellular reticular formation are critically involved in hippocampal synchronization. The exact course by which cells of the MMRF ultimately exert a synchronizing influence on the hippocampus is unknown, although it is thought to be by way of the medial septum. A direct connection between MMRF cells and the hippocampus has recently been demonstrated (Riley et al. 1979; Winson 1979; Wyss et al. 1979) and it is possible that these reticulo-hippocampal fibers may play a role in the synchronizing process.

\section{Summary}

In previous reports (Vertes 1977, 1979) we have shown that cells of the medial magnocellular reticular formation (MMRF) discharge at high rates of activity during both wakingmovement and REM sleep and at low rates during quiet waking and slow wave sleep. We suggested that some of these reticular cells may be involved in the generation of the hippocampal theta rhythm since they fire maximally during the identical states (general movement and REM sleep) in which theta is present in the hippocampus of the rat. In the present study the influence of the brain stem on the hippocampus was analyzed by systematically mapping the entire brain stem with stimulation to determine its effect on hippocampal slow wave activity. The results showed that the most effective stimulation sites for eliciting hippocampal synchronization were those within the medial magnocellular reticular formation and in or near the medial longitudinal fasciculus (MLF) at the level of the pons. These results suggest that cells of the MMRF are critically involved in hippocampal theta generation and that the fibers of these theta-eliciting cells primarily ascend in the MLF in their route rostrally from the brain stem.

\section{Résumé}

L'activation de l'hippocampe par le tronc cérébral: un rôle pour la formation réticulaire magnocellulaire et pour le MLF

Dans de récents articles (Vertes 1977, 1979) nous avons démontré que les grosses cellules de la formation réticulaire médiane 
(MMRF) se déchargent à des taux d'activité très élevés, pendant l'état de veille mobile et pendant le sommeil REM (sommeil paradoxal), et à des taux faibles durant l'état de veille tranquille et le sommeil à ondes lentes. Nous avons présumé que certaines de ces cellules réticulaires étaient impliquées dans la genèse des rythmes thêta hippocampiques puisqu'elles se déchargent au maximum pendant les mêmes états (mouvements généraux et sommeil REM) que ceux où l'activité thêta existe dans l'hippocampe du rat. Dans l'étude présente, l'influence du tronc cérébral sur l'hippocampe a été analysée, après examen systématique de tout le tronc, qui a été stimulé afin de déterminer les effets de cette stimulation sur l'activité lente hippocampique. Les résultats ont montré que les points de stimulation les plus efficaces pour déclencher la synchronisation hippocampique étaient ceux situés à l'intérieur de la formation réticulaire médiane magnocellulaire (MMRF) et dans le faisceau longitudinal médian, ou près de celui-ci, au niveau du pont. Ces résultats suggèrent que les cellules de la MMRF ont un rôle stratégique très important dans la création de l'activité thêta hippocampique et que les fibres de ces cellules, qui entraînent l'activité thêta, montent dans le MLF en suivant un chemin rostral à partir du tronc cérébral.

I thank Dr. Kenneth L. Casey for his critical reading of this manuscript.

\section{References}

Arnolds, D.E.A.T., Lopes da Silva, F.H., Aitink, W. and Kamp, A. Motor acts and firing of reticular neurons correlated with operantly reinforced theta shifts. Brain Res., 1977, 19: 377-380.

Assaf, S.Y. and Miller, J.J. The role of a raphe serotonin system in the control of septal unit activity and hippocampal desynchronization. Neuroscience, 1978, 3: 539-550.

Azmitia, E.C. and Segal, M. An autoradiographic analysis of the differential ascending projections of the dorsal and median raphe in the rat. J. comp. Neurol., 1978, 179: 641-668.

Bennett, T.L. Evidence against the theory that hippo- campal theta is a correlate of voluntary movement. Commun. Behav. Biol., 1969, 4 : 165-169.

Bernston, G.G. and Micco, D.J. Organization of brainstem behavioral systems. Brain Res. Bull., 1976, 1: $471-483$.

Bland, B.H. and Wishaw, I.Q. Generators and topography of hippocampal theta (RSA) in the anesthetized and freely moving rat. Brain Res., 1976, 118: 259-280.

Brodal, A. and Pompeiano, O. The origin of ascending fibers of the medial longitudinal fasciculus from the vestibular nuclei: an experimental study in the cat. Acta morph. neerl.-scand., 1957, 1: 306-328.

Buttner-Ennever, J.A. and Henn, V. An autoradiographic study of the pathways from the pontine reticular formation involved in horizontal eye movements. Brain Res., 1976, 108: 155-164.

Carpenter, M. Central oculomotor pathways. In: P. Bach y Rita, C.C. Collins and J.E. Hyde (Eds.), The Control of Eye Movements. Academic Press, New York, 1971: 67-103.

Conrad, L.C.A., Leonard, C.M. and Pfaff, D. W. Connections of the median and dorsal raphe nuclei in the rat: an autoradiographic and degeneration study. J. comp. Neurol., 1974, 156: 179-206.

Foote, S.L., Bloom, F.E. and Schwartz, A. Behavioral and electroencephalographic correlates of locus coeruleus neuronal discharge activity in the unanesthetized squirrel monkey. Neurosci. Abstr., 1978, 4: 272.

Graybiel, A. Direct and indirect preoculomotor pathways of the brainstem: an autoradiographic study of the pontine reticular formation in the cat. $J$. comp. Neurol., 1977, 175: 37-78.

Jones, G., Foote, S.L., Segal, M. and Bloom, F. Locus coeruleus neurons in freely behaving rats exhibit pronounced alterations of firing rate during sensory stimulation and stages of the sleep-wake cycle. Neurosci. Abstr., 1978, 4: 274.

Klemm, W.R. Effects of electric stimulation of brain stem reticular formation on hippocampal theta rhythm and muscle activity in unanesthetized, cervical and midbrain-transected rats. Brain Res., 1972, 41 : 331-344.

Macadar, A.W., Chalupa, L.M. and Lindsley, D.B. Differentiation of brain stem loci which affect hippocampal and neocortical electrical activity. Exp. Neurol., 1974, 41: 499-514.

Maru, E., Takahashi, L.K. and Iwahara, S. Effects of median raphe nucleus lesions on hippocampal EEG in the freely moving rat. Brain Res., 1979, 163: $223-234$.

Matano, S. Experimental studies on the medial longitudinal fasciculus in the rabbit. V. Ascending fibers from the reticular formation and the oculomotor system. J. Hirnforsch., 1970, 12: 241-253.

McMasters, R.E., Weiss, A.H. and Carpenter, M.B. Vestibular projections to the nuclei of the extra- 
ocular muscles. Degeneration resulting from discrete partial lesions of the vestibular nuclei in the monkey. Amer. J. Anat., 1966, 118: 163-194.

Nauta, W.J.H. and Kuypers, H.G.J.M. Some ascending pathways in the brain-stem reticular formation. In: H.H. Jasper, L.D. Proctor, R.S. Knighton, W.C. Noshay and R.T. Costello (Eds.), Reticular Formation of the Brain. Little, Brown, Boston, Mass., 1958: $319-340$.

Nozue, M. and Cohen, B. The role of the median longitudinal fasciculus in horizontal eye movements. Fed. Proc., 1968, $27: 451$.

Paiva, T., Lopes da Silva, F.H. and Mollevanger, W. Modulating systems of hippocampal EEG. Electroenceph. clin. Neurophysiol., 1976, 40: 470-480.

Palkovits, M. and Jacobowitz, D.M. Topographic atlas of catecholamine and acetylcholinesterase-containing neurons in the rat brain. Hindbrain. J. comp. Neurol., 1974, 157: 29-42.

Petsche, H., Stumpf, C.H. and Gogolak, G. The significance of the rabbit's septum as a relay station between the midbrain and the hippocampus. I. The control of hippocampus arousal activity by the septum cells. Electroenceph. clin. Neurophysiol., 1962, 14: 202-211.

Petsche, H., Gogolak, G. and Van Zwieten, P.A. Rhythmicity of septal cell discharges at various levels of reticular excitation. Electroenceph. clin. Neurophysiol., 1965, 19: 25-33.

Polc, $P$. and Monnier, M. An activating mechanism in the ponto-bulbar raphe system of the rabbit. Brain Res., 1970, 22: 47-61.

Remmel, R.S., Pola, J. and Skinner, R.D. Pontomedullary reticular projections into the region of the ascending medial longitudinal fasciculus in cat. Exp. Brain Res., 1978, 32: 31-37.

Riley, J.N., Marchand, E.R. and Moore, R.Y. Diencephalic and brainstem afferents to the hippocampal formation of the rat. Neurosci. Abstr., 1979, $5: 281$.

Robinson, T.E. Electrical stimulation of the brain stem in freely moving rats. I. Effects on behavior. Physiol. Behav., 1978, 21: 223-231.

Robinson, T.E. and Vanderwolf, C.H. Electrical stimulation of the brain stem in freely moving rats. II. Effects on hippocampal and neocortical electrical activity, and relations to behavior. Exp. Neurol., 1978, $61: 485-515$.

Siegel, J.M. and McGinty, D.J. Pontine reticular formation neurons: relationship of discharge to motor activity. Science, 1977, 196:678-679.

Stumpf, C.H., Petsche, H. and Gogolak, G. The significance of the rabbit's septum as a relay station between the midbrain and the hippocampus. II. The differential influence of drugs upon the septal cell firing pattern and the hippocampus theta activity. Electroenceph. clin. Neurophysiol., 1962, 14: $212-219$.

Vanderwolf, C.H. Hippocampal electrical activity and voluntary movement in the rat. Electroenceph. clin. Neurophysiol., 1969, 26: 407-418.

Vertes, R.P..Selective firing of rat pontine gigantocellular neurons during movement and REM sleep. Brain Res., 1977, 128: 146-152.

Vertes, R.P. Brain stem gigantocellular neurons: patterns of activity during behavior and sleep in the freely moving rat. J. Neurophysiol., 1979, 42: 214-228.

Walberg, F. Crossed reticulo-reticular projections in the medulla, pons and mesencephalon. An autoradiographic study in the cat. Z. Anat. Entwickl.Gesch., 1974, 143: 127-134.

Ward, A.A. Efferent functions of the reticular formation. In: H.H. Jasper, L.D. Proctor, R.S. Knighton, W.C. Noshay and R.T. Costello (Eds.), Reticular Formation of the Brain. Little, Brown, Boston, Mass., 1958: 263-273.

Winson, J. Interspecies differences in the occurrence of theta. Behav. Biol., 1972, 7: 479-487.

Winson, J. Patterns of hippocampal theta rhythm in the freely moving rat. Electroenceph. clin. Neurophysiol., 1974, 36: 291-301.

Winson, J. Hippocampal theta rhythm. I. Depth profiles in the curarized rat. Brain Res., 1976, 103: $57-70$.

Winson, J. Neuronal transmission from perforant pathway through dentate gyrus: dual brainstem activating system. Neurosci. Abstr., 1979, 5: 285.

Wyss, J.M., Swanson, L.W. and Cowan, W.M. A study of subcortical afferents to the hippocampal formation in the rat. Neuroscience, 1979, 4: 463-476. 